\title{
Tuz Stresi Altında Yetiștirilen Patlıcan Bitkilerinde Klorofil, Yaprak Su Potansiyeli ve Bazı Meyve Özellikleri Üzerine Așılı Bitki Kullanımının Etkisi
}

\author{
Manar Talhouni' \\ Șebnem Kușvuran² \\ Sevinç Kıran ${ }^{3, *}$

\begin{abstract}
'National Center for Agricultural Research and Extension, Amman
\end{abstract} \\ ${ }^{2}$ Çankırı Karatekin Üniversitesi, Kızılırmak Meslek Yüksekokulu, Çankırı \\ ${ }^{3}$ Toprak Gübre ve Su Kaynakları Merkez Araștırma Enstitüsü, Ankara \\ ${ }^{4}$ Ankara Üniversitesi, Ziraat Fakültesi, Bahçe Bitkileri Bölümü, Ankara
}

Ș. Șebnem Ellialtıoğlu

\begin{abstract}
*Sorumlu yazar e-mail (Corresponding author e-mail): sevinckiran@tgae.gov.tr Geliș tarihi (Received) : 13.12.2018

Kabul tarihi (Accepted): 04.03.2019

DOI : 10.21657/topraksu.544665
\end{abstract}

\section{Öz}

Tuzluluğa bağı verim ve kalite kaybı diğer sebzelerde olduğu gibi patıcan için de önemli bir sorundur. Patlıcan (Solanum melongena L.), tuza karșı orta derecede hassas bir bitkidir. Tuzluluk stresinin neden olduğu, verim kaybını ortadan kaldırmak veya azaltmak için kullanılan önemli yöntemlerden biri așılamadır. Araștırmada Vista, AGR703 (S. aethiopicum), Köksal $F_{1}$, Yula $F_{1}$, Vista (S. incanum x S. melongena hybrids) ve Hawk (S. torvum) ile tuza ve kurağa tolerant olduğu bilinen Mardin ve Burdur ıslah hatları (S. melongena L.) anaç olarak; tuza hassas Artvin yerel genotipi ile Naomi F, çeșidi kalem olarak kullanılmıștır. Kalem olarak kullanılan çeșitler ile așısız, kendi üzerine ve anaçlar üzerine așılanarak 18 anaç/kalem kombinasyonu olușturulmuștur. Bitkilerin yetiștirilmesinde damla sulama yöntemi kullanılarak, EC 1.8-2.0 dSm-1 ve pH 5-6 özelliğindeki su ile (kontrol suyu) sulanma yapılmıștır. Bitkiler çiçeklenme ve meyve tutumu așamasına geldiğinde 3 bin litrelik PE (polietilen) depo içine $8.76 \mathrm{~kg} \mathrm{NaCl}$ (90 mM) ilave edilmiș (EC 6-7 dSm${ }^{-1}$ ) ve bu depodan stres grubu bitkilere bir gün tuzlu su, bir gün kontrol suyu verilmiștir. Araștırma sonucunda; klorofil içeriği, toplam verim, ortalama meyve ağırlığı, meyve suyu $\mathrm{pH}$ değeri, toplam suda çözünebilir madde miktarı, titre edilebilir asit miktarı ve meyvelerde renk ölçümü değerleri bakımından uygulama çeșit interaksiyonu istatistiki olarak önemli bulunmuștur. Bununla birlikte ortalama meyve çapı değerleri bakımından kombinasyon ve uygulamalar arası, yaprak su potansiyeli değerleri bakımından uygulamalar arası farklıık önemli bulunmuștur. Kalem olarak kullanılan Naomi $F_{1}$ ticari çeșidi, Artvin yerel genotipine göre daha iyi sonuçlar verdiği, anaç olarak kullanılan ticari çeșitler içinde Köksal $F_{1}$ ve Vista $F_{1}$ çeșitlerinin öne çıktığı belirlenmiștir. Sonuç olarak anaç olarak kullanılan Burdur ıslah hattının anaç ıslahında kullanılabilecek bir genotip olduğu tespit edilmiștir.

Anahtar kelimeler: Patlıcan, stres, așı, anaç

\section{Effects of Grafting on Eggplants Grown under Salinity Stress in Terms of Chlorophyll Content, Leaf Water Potential and Some Fruit Characteristics}

\begin{abstract}
Eggplant (Solanum melongena L.); the third most important vegetable crop after potato and tomato; is relatively salt sensitive. Grafting over tolerant rootstocks proved to be an effective tool, among others, to alleviate negative effects of salinity upon vegetable crops by increasing plants tolerance against salinity. In this study, different rootstock/scion eggplant combinations were obtained as follow; Five
\end{abstract}


commercial rootstocks (AGR 703 (S. aethiopicum), Vista, Köksal $F_{1}$, Yula $F_{1}$ (S. incanum x S. melongena hybrids) and Hawk (S. torvum)), in addition to two Turkish genotypes Burdur and Mardin (S. melongena L.) were used as the rootstocks. For scion two cultivars were used (Artvin and Naomi $F_{1}$ ). Self-grafted and non-grafted seedlings were used as control. In total 18 combinations were obtained. Grafted plants where grown under two salinity treatments 1.8-2 dSm${ }^{-1}$ (control) and 5-6 dSm${ }^{-1}$ (stress) in pots under greenhouse conditions. Salinity treatment started when plants were at the flowering stage by adding $\mathrm{NaCl}$ to the nutriontion solution applied through drip irrigation system. $\mathrm{NaCl}$ was used as the salinity source by adding $8.76 \mathrm{Kg} \mathrm{NaCl}(90 \mathrm{mM})$ to 3000 lit irrigation tank designated to plants group under stress. Plants in the stress treatment were irrigated with saline water every other day. Total yield, average fruit weight, leaf chlorophyll content, fruit total soluble solids (TSS) and titratable acidity (TA), fruit weight and diameter, fruit color and $\mathrm{pH}$ parameters were tested and the genotype $\mathrm{x}$ treatment interaction was found to be significant. Salinity had negative effects on the parametrers measured. In terms of average fruit diameter values, significant differences were found between treatment (salinity) and grafting combinations, in addition the difference between the treatments in terms of leaf water potential values was found to be significant. Naomi Fi genotype was found superior compared to Artvin genotype as a scion, while between rootstocks Köksal $F_{\text {, }}$ and Vista $F_{\text {, genotypes were found }}$ significantly superior among the other comercial genotypes used.

Key word: Eggplant, stress, grafting, rootstock

\section{Gíriș}

Patlıcan, dünyada 1.871 milyon hektar alanda 50.193 milyon ton, Türkiye'de yaklașı 27 bin hektar alanda 827 bin ton olarak üretilen, Solanaceae familyasına ait, ticari değere sahip olduğu kadar içerdiği vitaminler, antioksidanlar, mineral maddeler ile sağık yönünden de değerli bir sebzedir (TUIK 2017). Tropik ve subtropik ekolojilerde ve Akdeniz havzasında bolca yetiștirilen bir sebze türüdür. Hindistan'ın da içinde yer aldığı Hint Yarımadası kökenli bir tür olarak bilinen patlıcanın; Çin, Hindistan veya Tayland'da kültüre alındığı tahmin edilmektedir. Anadolu'ya İpek Yolu ile yapılan ticaret sayesinde geldiği tahmin edilmekte olup geçmișten günümüze hem sebze hem de tıbbi bitki olarak kullanılmıștır (Daunay ve Janick, 2007; Boyacı 2008). Türkiye'deki patlıcan üretiminin yaklașık \%20'si örtü altında yapılmaktadır. Taze olarak tüketildiği gibi kurutularak, közlenerek, ve dondurularak muhafaza edilmektedir (Çürük vd., 2010; Tümbilen vd., 20111.

Sebze tarımının yoğun olarakyapııdığı alanlarda verim ve kalite kaybına yol açan en önemli faktörlerden biri toprak tuzluluğudur. Abiyotik stres faktörlerinden olan tuzluluğa tolerant çeșit ıslahındaki bașarı her zaman istenilen düzeyde olamamaktadır. Abiyotik streslere tolerans amaçlandığında ıslah süresi uzun ve zorlayıcıdır. Ayrıca kalıtımın çok genli, kantitatif bir özellik olması sebebiyle hedefe kolayca ulașmak her

zaman mümkün değildir. Anaç kullanımı ve așılı bitki ile yapılan yetiștiricilik, alternatif bir çözüm olarak öne çıkmaktadır. Anaç üzerine așılanmıș fidelerin kullanıldığı sebze yetiștiriciliği birçok türde biyotik ve abiyotik stres faktörleri ile bașa çıkmada etkin bir yol olarak düșünülmektedir.

Tuzluluk, özellikle kurak ve yarı kurak iklimlerde bitki gelișimini ve ürün verimini etkileyen en yaygın çevresel tehditlerden bir tanesidir (Turhan vd., 2009; Colla vd., 2010). Tuzluluk örtü altı yetiștiricilik alanlarında, açıkta yetiștiricilikten çok daha etkin olmaktadır. Topraksız sistemlerde dahi düșük kaliteli su kullanımı tuzluluk açısından sorunlara neden olmaktadır (Oztekin, 2011). Așılama, sebze yetiștiriciliğinde ilk olarak abiyotik stres koșullarına karșı kullanılımıștır (Eisavd., 2012). Așlı bitkiler, güçlü kök yapıları sayesinde tuz stresine karșı dayanıkılıık göstermektedir (Fernandez-Garcia vd.,2003; Estan vd., 2005). Kalem ya da çeșit, meyve verim ve kalitesinden sorumlu etken iken anaç, kök sisteminde avantajlar sağlamakta, bununla birlikte ürün üzerinde etkilere sahip olabilmektedir. Bu yüzden anaç-kalem kombinasyonları, iklim ve yer özellikleri dikkate alınarak doğru tespit edilmelidir. Sebzelerde așilamada kullanılan anaçların büyük çoğunluğu aynı türün yabani formları olup, bu yabani formlar arasında tür içi veya türler arası melezlemeler ile elde edilmiș hibrit anaçlar güçlü yapılarından dolayı fayda sağlamaktadır (Savvas vd., 2010; King vd., 2010). 
Patlıcanda așılı bitki kullanımının ve anaç/kalem kombinasyonlarının tuz stresine toleransı artırma üzerindeki etkilerinin incelendiği bu araștırmada; patlıcanda ticari olarak kullanılan ve yabani tür kökenli anaçlar ile tuza toleranslı yerel patıcan genotipleri üzerine yapılan așılamanın, tuz stresi altında yetiștirilen tuza hassas bir yerel genotip ve ticari bir F1 patlıcan çeșidinin tuzdan etkilenme durumunu ortaya koymak amaçlanmıștır. Burada sunulan sonuçlar, farklı anaç/kalem kombinasyonlarında tuz uygulamalarının klorofil, yaprak su potansiyeli ve bazı meyve özelliklerine olan etkilerini kapsamaktadır.

\section{MATERYAL VE YÖNTEM}

Araștırma 2014 yılında Antalya'da plastik örtülü araștırma serasında yürütülmüștür. Araștırmada kullanılan bitkisel materyal olarak Vista (S. melongena), AGR703 (S.torvum), Köksal F1 (S. aeriticum $x$ S.melongena), Yula $F_{1}$ (S. incanum $x$ S. melongena hibritleri ), Hawk (S.torvum) ticari patlıcan anaçları ile tuza ve kurağa tolerant olduğu bilinen (Yașar, 2003), Mardin ve Burdur ıslah hatları (anaç olarak) ve tuza hassas Artvin yerel genotipi ile Naomi $F_{1}$ ticari çeșidi (kalem olarak) kullanıımıștır. Naomi $F_{1}$ ve Artvin genotiplerinin anaçlarla ayrı ayrı așılanmasıyla olușturulan 14 kombinasyona ilaveten tek bașına așılama ișleminin tuz toleransına etkisini belirlemek için kendi üzerine așllı 2 kombinasyon daha elde edilmiștir. Ayrıca anaç etkisini belirlemek amacıyla kalemler așısız olarak da çalıșmaya dahil edildiğinde toplam 18 farklı kombinasyon ortaya çıkmıștır. Așılı ve așısız tüm patlıcan fideleri, 1:1 oranında perlit: vermikulit içeren 8 L'lik saksılara dikilmiștir. Olușturulan kombinasyonlar kontrol ve tuz uygulaması olarak tesadüf parselleri deneme desenine göre iki gruba ayrılmıș, üç tekerrürlü, her tekerrürde 3 bitki, sıra arası $80 \mathrm{~cm}$ ve sıra üzeri 60 $\mathrm{cm}$ olacak șekilde rastgele yerleștirilmiștir. Her iki grup, dikimden itibaren 40 gün boyunca Hoagland besin çözeltisi $\left(\mathrm{KNO}_{3}: 1020 \mathrm{ppm}, \mathrm{Ca}\left(\mathrm{NO}_{3}\right)_{2}\right.$ : $492 \mathrm{ppm}, \mathrm{NH}_{4} \mathrm{H}_{2} \mathrm{PO}_{4}: 230 \mathrm{ppm}, \mathrm{MgSO}_{4} \cdot 7 \mathrm{H}_{2} \mathrm{O}$ : 420 ppm, $\mathrm{H}_{3} \mathrm{BO}_{3}: 2.86 \mathrm{ppm}, \mathrm{MnCl}_{2} \cdot 4 \mathrm{H}_{2} \mathrm{O}: 1.81$ ppm, $\mathrm{H}_{2} \mathrm{MoO}_{4} \cdot \mathrm{H}_{2} \mathrm{O}: 0.09 \mathrm{ppm}, \mathrm{FeSO}_{4} \cdot \mathrm{H}_{2} \mathrm{O}: 0.07$ ppm, $\left.(\mathrm{CHOH})_{2}(\mathrm{COOH})_{2}: 0.02 \mathrm{ppm}\right)$ ile sulanmıș olup bitkilerin tek gövde üzerinde normal olarak dallanmasına izin verilmiștir. Damla sulama yönteminde kullanılan su, yeraltı su kuyusundan elde edilmiștir ve bu suya ait özellikler EC 1.8-2.0 dS $\mathrm{m}^{-1}$; $\mathrm{pH}$ 5-6'dır. Bitkiler çiçeklenme ve meyve tutumu așamasına gelindiğinde 3 bin litrelik PE su deposu içine $8.76 \mathrm{~kg} \mathrm{NaCl}(90 \mathrm{mM}$; EC 6-7 $\mathrm{dS} \mathrm{m}^{-1}$ ) ilave edilmiș ve bu depodan stres grubu bitkilere bir gün tuzlu su bir gün kontrol suyu verilmiștir. Așırı tuz birikimini önlemek amacıyla saksı altlarından serbest drenaj uygulanmıștır. Saksı altlıklarında toplanan sular, ortamdaki EC dozunu sabit tutmak amacıyla EC metre yardımıyla her sulama sonrası ölçülmüștür. İlk hasat yapıldığında (tuzlu sulama uygulamasından 40 gün sonra), içeriği zenginleștirilmiș olan ikinci besin çözeltisi kullanıımaya bașlanmıștır. Besin çözeltilerinin belirlenmesinde Libia vd. (2012), Aktas vd. (2013) ile Genta Tarım A.Ș. yetiștiricilik uygulamalarından yararlanılmıștır (Karaçalı, 1993; Altunlu, 2011).

\section{Ölçüm ve Analizler:}

Klorofil içeriği: İkinci meyve hasadının yapıldığı dönemde bitkinin büyüme ucundan geriye doğru alınan üçüncü yapraktan hazırlanan 200 mg örnek, \%80'lik asetonda homojenize edilmiștir. Filtrasyondan sonra aseton ile 10 ml'ye tamamlanan örneklerde spektorfotometrede (Analytic jenan 40) 652 nm'de ölçüm yapılımıștır.

Klorofil miktarı = ABS değerix2.78xHacim 110 ml) /Taze AğırlıkX1000 formülü ile hesaplanmıștır.

Yaprak su potansiyeli: Bitkilerden alınan yaprak örneklerinde Model 1000 PMS Instrument Com. cihazı ile ölçümler yapılarak, yaprak su potansiyelleri belirlenmiștir.

Bitki bașına toplam verim (kg/bitki): Her uygulama konusuna ait bitkilerde ilk hasattan son hasat tarihine kadar olan süre içerisinde toplanan meyveler tartılarak toplam değeri bulunmuș ve bu değer bitki sayısına bölünmüștür.

Ortalama meyve ağırlığı (g): Her bir uygulama konusundan hasat edilen tüm meyvelerin ağırıkları meyve sayısına bölünerek hesaplanmıștır ve $g$ olarak ifade edilmiștir.

Ortalama meyve çapı (mm): Uygulamalara ait bitki örneklerinden hasat edilen tüm meyvelerin orta noktalarından dijital kumpas ile çapları ölçülmüștür ve mm olarak ifade edilmiștir.

Meyve kalitesini belirlemek amacıyla, bitki üzerinde 2. salkımda olușan meyveler antezis döneminden itibaren 4 haftalık olduklarında hasat edilerek analizler yapılmıștır. Meyve örnekleri blender ile parçalanmıș ve elde edilen meyve püreleri filtre kağıdından geçirilerek süzülmüștür (Altunlu, 2011). Buna göre; 
Meyve suyu pH değeri: Süzüğe batırılan el tipi WTW pH metre probu ile yapılan ölçümler sonucunda elde edilmiștir.

Toplam suda çözünebilir madde miktarı (TSÇKM) (\%): Süzükten alınan birkaç damla örnek dijital el refraktometresi ile okunmuș ve sonuçlar \% olarak verilmiștir.

Titre edilebilir asit (TA) miktarı (mval/100 $\mathbf{m l}$ ): Süzükten alınan $5 \mathrm{ml}$ örneğe $10 \mathrm{ml}$ saf su konmuș, 0.1 N NaOH çözeltisi ile 8.01 pH değeri elde edilinceye kadar titrasyon yapılmıștır. Titre edilebilir asit değeri, harcanan $\mathrm{NaOH}$ miktarı üzerinden formülle hesaplanmıștır (Karaçalı, 1993; Altunlu,2011).

Meyvelerde renk ölçümü: Meyve dıș rengi belirleme çalıșmalarında Konika Minolta CR 200 renkölçer cihazından faydalanıımıștır. Minolta cihazı ile yapılan ölçümlerde Sönmez (2014) tarafından açıklanan yöntem ve formülasyon kullanıımıștır.

\section{BULGULAR VE TARTIȘMA \\ Klorofil miktarı bakımından ortaya çıkan değișimler}

Tuz uygulamasından 60 gün sonra bitkilerden alınan örneklerde yapılan ölçümler sonucu klorofil konsantrasyonunda kontrol bitkilerine göre azalma belirlenmiș ve değerler $44.47 \pm 0.03$ $\mu \mathrm{g} / \mathrm{mg}$ TA (Köksal/Artvin) ile 39.43 $\pm 0.21 \mu \mathrm{g} / \mathrm{mg}$ TA (Naomi) arasında bulunmuștur (Çizelge 1). Uygulamalar arasındaki ve așı kombinasyonları arasındaki farklılık istatistiksel olarak $p \leq 0.01$ düzeyinde önemlilik göstermiș, 'uygulama $x$ kombinasyon' interaksiyonu da önemli bulunmuștur. Kendi üzerine așılı bitkilerin klorofil miktarları en düșük gruplara (așısız olanlar) yakın istatistiksel değerler vermiștir. Elde edilen değerler önceki çalıșmalarla benzerlik göstermektedir.

Çizelge 1. Tuz uygulamasından 60 gün sonra klorofil miktarı ( $\mu \mathrm{g} / \mathrm{mg}$ TA) ve yaprak su potansiyeli (-bar) değerleri Table 1. Chlorophyll content ( $\mathrm{gg} / \mathrm{mg}$ FW) and leaf water potential (-bar) values 60 days later after salt treatment

\begin{tabular}{|c|c|c|c|c|}
\hline \multirow{2}{*}{ Kombinasyonlar } & \multicolumn{2}{|c|}{ Klorofil ( $\mu \mathrm{g} / \mathrm{mg}$ ) } & \multicolumn{2}{|c|}{ Yaprak Su Potansiyeli (-bar) } \\
\hline & Kontrol & Tuz & Kontrol & Tuz \\
\hline Köksal/Artvin & $52.47 \pm 1.90 \mathrm{~h}$ & $44.47 \pm 0.03 k$ & $13.43 \pm 0.81 \mathrm{a}$ & $17.54 \pm 3.62 \mathrm{a}$ \\
\hline AGR703/Artvin & $49.82 \pm 0.07 \mathrm{~g}$ & $44.42 \pm 0.03 k$ & $13.04 \pm 1.30 \mathrm{a}$ & $17.08 \pm 3.93 \mathrm{a}$ \\
\hline Vista/Artvin & $48.55 \pm 0.13 \mathrm{~d}-\mathrm{g}$ & $43.62 \pm 0.07 \mathrm{hi}$ & $12.45 \pm 2.91$ а & $16.46 \pm 1.47 \mathrm{a}$ \\
\hline Yula/Artvin & $47.43 \pm 0.08$ a-d & $41.85 \pm 0.17$ ef & $13.65 \pm 1.16$ a & $17.59 \pm 2.01 \mathrm{a}$ \\
\hline Burdur/Artvin & $49.01 \pm 0.01 \mathrm{e}-\mathrm{g}$ & $44.16 \pm 0.06 \mathrm{jk}$ & $13.43 \pm 1.59$ a & $17.18 \pm 2.91 \mathrm{a}$ \\
\hline Mardin/Artvin & $48.19 \pm 0.04 c-f$ & $43.30 \pm 0.08 \mathrm{~h}$ & $12.67 \pm 1.98$ a & $16.76 \pm 1.44 a$ \\
\hline Hawk/Artvin & $48.37 \pm 0.06 c-f$ & $43.48 \pm 0.04$ hi & $12.54 \pm 2.94$ а & $16.69 \pm 2.08$ a \\
\hline Artvin/Artvin & $47.12 \pm 0.08$ a-c & $41.14 \pm 0.36 d$ & $12.55 \pm 2.72$ а & $18.30 \pm 3.00$ a \\
\hline Artvin & $46.68 \pm 0.03 \mathrm{ab}$ & $40.08 \pm 0.33 \mathrm{~b}$ & $13.04 \pm 3.52$ a & $19.68 \pm 2.56$ a \\
\hline Köksal//Naomi & $49.48 \pm 0.20 \mathrm{fg}$ & $44.35 \pm 0.05 k$ & $12.76 \pm 2.02 \mathrm{a}$ & $16.68 \pm 2.63 \mathrm{a}$ \\
\hline AGR703/Naomi & $48.85 \pm 0.05 \mathrm{e}-\mathrm{g}$ & $43.70 \pm 0.00 \mathrm{hi}$ & $12.88 \pm 0.95 a$ & $16.67 \pm 1.09$ a \\
\hline Vista/Naomi & $48.10 \pm 0.00 c-f$ & $42.84 \pm 0.14 \mathrm{~g}$ & $13.35 \pm 2.40$ а & $17.18 \pm 1.90$ a \\
\hline Yula/Naomi & $47.68 \pm 0.08$ a-e & $42.17 \pm 0.06 \mathrm{f}$ & $12.31 \pm 3.17$ a & $17.34 \pm 0.94$ a \\
\hline Burdur/Naomi & $48.93 \pm 0.06 \mathrm{e}-\mathrm{g}$ & $43.89 \pm 0.08 \mathrm{ij}$ & $13.53 \pm 2.21$ a & $17.83 \pm 2.81$ a \\
\hline Mardin/Naomi & $48.00 \pm 0.10$ b-e & $42.63 \pm 0.08 \mathrm{~g}$ & $13.87 \pm 2.34$ а & $19.47 \pm 1.41 \mathrm{a}$ \\
\hline Hawk/Naomi & $47.28 \pm 0.03$ a-d & $41.55 \pm 0.13 \mathrm{de}$ & $12.45 \pm 3.42 \mathrm{a}$ & $15.92 \pm 0.33$ a \\
\hline Naomi/Naomi & $47.00 \pm 0.01$ a-c & $40.55 \pm 0.05 \mathrm{c}$ & $12.98 \pm 1.08$ а & $18.70 \pm 0.46 a$ \\
\hline Naomi & $46.53 \pm 0.06$ a & $39.43 \pm 0.21$ a & $13.33 \pm 3.21$ a & $19.86 \pm 2.03$ a \\
\hline$C V(\%)$ & 2.09 & 3.69 & 3.60 & 6.57 \\
\hline Uygulama & \multicolumn{2}{|c|}{$* *$} & \multicolumn{2}{|c|}{$* *$} \\
\hline Kombinasyon & \multicolumn{2}{|c|}{$\star *$} & \multicolumn{2}{|c|}{ ÖD } \\
\hline Kombinasyon X & \multirow{2}{*}{\multicolumn{2}{|c|}{$* *$}} & \multirow{2}{*}{\multicolumn{2}{|c|}{ ÖD }} \\
\hline Uygulama & & & & \\
\hline
\end{tabular}

Aynı sütunda farklı harfi alan ortalamalar arasındaki farklılık önemlidir ( $\mathrm{\rho} \leq 0.01)$. Ortalamalar arası farklııklar Duncan testi ile belirlenmiștir. **: P $\leq 0.01$ olasıllık düzeyinde önemlidir. *: P $\leq 0.05$ olasılık düzeyinde önemlidir. ÖD: önemli değil 
Tuz stresinde yapraklarda renk açılması, sararma ve en sonunda nekroze olan dokular tipik belirtilerdir. Klorofil miktarının tuz stresi altındaki bitkilerde azalmasının nedeni fotosentetik sistemin fonksiyonunu yitirmesidir. Böylece yașlanma meydana gelmiș, klorofil parçalanmıș ve fotosentez oranı düșmüștür (Sivritepe vd., 2010; Yașar vd., 2011 ; Sangtarashani vd., 2013).

\section{Yaprak su potansiyeli bakımından ortaya çıkan değișimler}

Așılı ve așısız pattıcan bitkilerinden olușturulan 18 farklı kombinasyona sahip kontrol ve tuz grubu arasındaki ve așı kombinasyonları arasındaki farklılık istatistiksel olarak $p \leq 0.01$ düzeyinde önemli bulunmuștur. Kontrol uygulamasındaki kombinasyonlar istatistiksel olarak aynı grup içerisinde yer almıșlardır. Tuz uygulaması yapılmayan bitkilerdeki yaprak su potansiyeli -12.45 ila -13.87 bar arasında değișirken, tuz uygulanan bitkilerde $-15.92 \pm 0.33$ ila $-19.86 \pm 2.03$ bar arasında değișmiștir. Tuzlu ortam bitkilerin yaprak su potansiyel değerlerinde azalmaya neden olmuștur. Bulunan sonuçlar önceki araștırma sonuçları ile uyumludur. Bitki stres koșulları altında madde birikimi sayesinde ozmotik potansiyelini düșürür ve su alım kapasitesinin artırır. Böylece turgor basıncı artar, hücre gelișmesi ve stomaların açılması sağlanır. Domateste (RomeroAranda vd.,2001; Hossain vd., 2012), kavunda (Kușvuran vd., 2011 ) tuz stresinin bitkilerde yaprak su potansiyelini azalttığını bildirmișlerdir.

\section{Meyve kabuk renk ölçümleri bakımından ortaya çıkan değișimler}

Kabuk renk değerleri (Chroma) bakımından 'uygulamaxkombinasyon' interaksiyonu önemli bulunmuștur. Anaçlar üzerine așılama yapıIması meyve rengi üzerinde farklıık yaratan bir etki olarak ortaya çıkmıș, bu etki kendi üzerine așılanan Artvin ve Naomi çeșitlerinde de meydana gelmiștir (Çizelge 2). Uygulamalar arasındaki ve așı kombinasyonları arasındaki farklılık istatistiksel olarak $p \leq 0.01$ düzeyinde önemlilik gösterdiği gibi, bu özellik bakımından 'uygulamaxkombinasyon' interaksiyonu da önemli bulunmuștur.

Çizelge 2. Tuz stresi uygulaması sonunda chroma ve hue açısı değerleri

Table 2. At the end of salt stress treatment, chroma and hue angle values

\begin{tabular}{|c|c|c|c|c|}
\hline \multirow{2}{*}{ Kombinasyonlar } & \multicolumn{2}{|c|}{ Chroma } & \multicolumn{2}{|c|}{ Hue } \\
\hline & Kontrol & Tuz & Kontrol & Tuz \\
\hline Köksal/Artvin & $15.31 \pm 1.74 \mathrm{C}$ & $21.01 \pm 2.05 \mathrm{~g}$ & $11.13 \pm 0.75 a$ & $9.15 \pm 1.66 \mathrm{ab}$ \\
\hline AGR703/Artvin & $15.73 \pm 1.71 \mathrm{C}$ & $19.11 \pm 2.04 \mathrm{fg}$ & $22.28 \pm 2.64 c$ & $17.07 \pm 1.61 \mathrm{ef}$ \\
\hline Vista/Artvin & $15.05 \pm 0.98 \mathrm{c}$ & $19.19 \pm 2.74 \mathrm{fg}$ & $23.99 \pm 2.66 \mathrm{~cd}$ & $18.75 \pm 1.65 \mathrm{fg}$ \\
\hline Yula/Artvin & $6.93 \pm 1.07$ а & $9.20 \pm 1.18 \mathrm{ab}$ & $14.27 \pm 2.17 \mathrm{ab}$ & $10.34 \pm 1.16$ a-c \\
\hline Burdur/Artvin & $16.14 \pm 1.12 \mathrm{C}$ & $19.28 \pm 2.25 \mathrm{fg}$ & $24.18 \pm 3.84 \mathrm{~cd}$ & $20.36 \pm 2.35 \mathrm{~g}$ \\
\hline Mardin/Artvin & $10.24 \pm 1.04 \mathrm{~b}$ & $14.22 \pm 2.09 \mathrm{~cd}$ & $15.26 \pm 1.31 \mathrm{~b}$ & $13.01 \pm 1.98 \mathrm{~cd}$ \\
\hline Hawk/Artvin & $16.58 \pm 1.17 \mathrm{C}$ & $18.38 \pm 1.53 \mathrm{e}-\mathrm{g}$ & $27.14 \pm 2.15 \mathrm{~d}$ & $19.45 \pm 1.83 \mathrm{fg}$ \\
\hline Artvin/Artvin & $6.39 \pm 0.86$ a & $6.83 \pm 1.15 a$ & $13.41 \pm 2.15 \mathrm{ab}$ & $8.23 \pm 1.67 a b$ \\
\hline Artvin & $15.22 \pm 2.26 \mathrm{c}$ & $16.73 \pm 1.40 \mathrm{~d}-\mathrm{f}$ & $13.97 \pm 2.85 \mathrm{ab}$ & $9.68 \pm 2.02 \mathrm{ab}$ \\
\hline Köksal/Naomi & $10.87 \pm 1.43 \mathrm{~b}$ & $11.93 \pm 1.31 \mathrm{bc}$ & $15.35 \pm 2.91 \mathrm{~b}$ & $10.53 \pm 2.08$ a-c \\
\hline AGR703/Naomi & $6.38 \pm 0.49$ а & $7.26 \pm 1.15$ a & $13.16 \pm 1.05 \mathrm{ab}$ & $7.66 \pm 1.08$ a \\
\hline Vista/Naomi & $6.17 \pm 0.89$ а & $6.99 \pm 0.97$ а & $13.52 \pm 1.49 \mathrm{ab}$ & $8.31 \pm 0.87$ ab \\
\hline Yula/Naomi & $6.32 \pm 1.43$ a & $6.62 \pm 0.81$ a & $13.34 \pm 2.98 \mathrm{ab}$ & $8.32 \pm 1.31 \mathrm{ab}$ \\
\hline Burdur/Naomi & $6.12 \pm 1.12$ a & $7.21 \pm 1.49$ a & $12.57 \pm 2.61 \mathrm{ab}$ & $8.95 \pm 2.26$ ab \\
\hline Mardin/Naomi & $9.55 \pm 1.26 \mathrm{~b}$ & $11.37 \pm 1.31 \mathrm{~b}$ & $14.93 \pm 1.85 \mathrm{ab}$ & $9.49 \pm 1.08$ ab \\
\hline Hawk/Naomi & $6.62 \pm 1.06$ a & $7.46 \pm 1.42$ a & $12.94 \pm 1.87 \mathrm{ab}$ & $10.72 \pm 1.85 \mathrm{~b}-\mathrm{c}$ \\
\hline Naomi/Naomi & $7.12 \pm 1.08$ а & $8.36 \pm 1.47$ a & $15.38 \pm 2.42$ b & $11.04 \pm 1.29 \mathrm{bc}$ \\
\hline Naomi & $15.28 \pm 0.98 \mathrm{c}$ & $16.35 \pm 1.88 \mathrm{de}$ & $20.57 \pm 1.06 c$ & $15.35 \pm 2.20 \mathrm{de}$ \\
\hline CV $(\%)$ & 40.30 & 42.23 & 29.09 & 35.26 \\
\hline Uygulama & \multicolumn{2}{|c|}{ ** } & \multicolumn{2}{|c|}{ ** } \\
\hline Kombinasyon & \multicolumn{2}{|c|}{ ** } & \multicolumn{2}{|c|}{ ** } \\
\hline $\begin{array}{l}\text { KombinasyonX } \\
\text { Uyqulama }\end{array}$ & \multicolumn{2}{|c|}{ ** } & \multicolumn{2}{|c|}{$* *$} \\
\hline
\end{tabular}


Renk ölçüm sonucunda tuz uygulanan bitkilerin değerlerinde artıș olduğu hue açı değerlerinde ise azalma olduğu tespit edilmiștir. Bu sonuçlara paralel olarak patlıcan kabuklarının mor renkten gri renk tonlarına doğru renk değiștirdiği belirlenmiștir. Kabuk renk tonu (hue) değerleri bakımından kontrol ve tuz uygulanan bitkiler içerisinde 'uygulamaxkombinasyon' interaksiyonları önemli bulunmuștur. Anaçlar üzerine așılama yapılması meyve rengi tonu üzerinde olumlu farklılık yaratan bir etki olup, bu etki kendi üzerine așılanan Artvin ve Naomi çeșitlerinin ikisinde de ortaya çıkmıștır (Çizelge 2).

Renk olușumu pek çok faktöre birden bağlı olarak ortaya çıkmaktadır. Bitkinin üzerindeki pozisyon ve kaçıncı meyve olduğu bile renk bakımından farklılıklara neden olabilmektedir. Bu nedenle renk ile ilgili ölçümlerin anaç seçiminde değerlendirmede ilk sıralarda yer almayacak bir parametre olduğu kanaatine varılmıștır. Borghesi vd. (2011) de, tuz stresi altında domates meyvelerinin dıș kabuk renginde belirgin düșüș olduğunu, bu düșüșlerin hassas genotiplerde daha fazla ortaya çıktığını belirtmișlerdir.

\section{Meyve suyu pH'sı bakımından ortaya çıkan değișimler}

Meyve suyunun $\mathrm{pH}$ değeri ile ilgili olarak uygulamalar arasındaki ve așı kombinasyonları arasındaki farklılık istatistiksel olarak $\mathrm{p} \leq 0.01$ düzeyinde önemlilik gösterdiği gibi, bu özellik bakımından 'uygulamaxkombinasyon' interaksiyonu da önemli bulunmuștur. Kontrol grubu bitkilerin meyvelerinden elde edilen

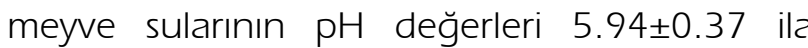
$6.41 \pm 0.34$ arasında değișmiș olup aralarında istatistiksel olarak önemli bir farklılık bulunmamıștır (Çizelge 3). Tuz uygulamasından yapılan meyve örneklerinden elde edilen $\mathrm{pH}$ değerinde azalmalar meydana gelmiș olup bu değerler arasında istatistiksel olarak farklılık ortaya çıkmıștır. En düșük pH değeri 4.67ะ0.23 ile kendi üzerine

Çizelge 3. Tuz stresi uygulaması sonunda meyve suyu pH, titre edilebilir asit (mval 100/ ml) ve TSÇKM (\%)' de ortaya çıkan değișim değerleri

Table 3. At the end of the salt stress treatment, the changed values on pH, titratable acid (mval $100 / \mathrm{ml}$ ) and TSKKM (\%) of fruit juice

\begin{tabular}{|c|c|c|c|c|c|c|}
\hline \multirow[t]{2}{*}{ Kombinasyonlar } & \multicolumn{2}{|c|}{ Meyve suyu pH } & \multicolumn{2}{|c|}{ Titre Edilebilir Asit } & \multicolumn{2}{|c|}{ TSCCKM } \\
\hline & Kontrol & Tuz & Kontrol & Tuz & Kontrol & Tuz \\
\hline Köksal/Artvin & $6.20 \pm 0.39$ а & $5.34 \pm 0.30 \mathrm{~b}-\mathrm{e}$ & $0.87 \pm 0.42$ а & $4.18 \pm 0.28 \mathrm{ef}$ & $4.33 \pm 0.23$ a & $6.05 \pm 0.40 \mathrm{~d}$ \\
\hline AGR703/Artvin & $6.10 \pm 0.60 \mathrm{a}$ & $5.46 \pm 0.75 \mathrm{de}$ & $0.83 \pm 0.36$ а & $4.37 \pm 0.32 \mathrm{e}-\mathrm{g}$ & $4.36 \pm 0.24 a$ & $6.08 \pm 0.99 \mathrm{~d}$ \\
\hline Vista/Artvin & $6.01 \pm 0.20$ a & $5.39 \pm 0.55 c-e$ & $0.72 \pm 0.60$ a & $4.23 \pm 0.39 \mathrm{e}-\mathrm{g}$ & $4.97 \pm 0.58$ a & $5.43 \pm 0.62 \mathrm{a}-\mathrm{d}$ \\
\hline Yula/Artvin & $6.04 \pm 0.39$ a & $5.45 \pm 0.48 \mathrm{de}$ & $0.89 \pm 0.39$ a & $2.60 \pm 0.35$ a & $4.09 \pm 0.62 \mathrm{a}$ & $5.62 \pm 0.38 \mathrm{~b}-\mathrm{d}$ \\
\hline Burdur/Artvin & $5.94 \pm 0.37$ a & $5.63 \pm 0.22 \mathrm{e}$ & $0.85 \pm 0.41$ a & $4.73 \pm 0.44 \mathrm{fg}$ & $4.54 \pm 0.35$ a & $5.30 \pm 0.50$ a-d \\
\hline Mardin/Artvin & $6.11 \pm 0.34$ a & $5.32 \pm 0.47$ a-e & $0.69 \pm 0.35$ a & $4.80 \pm 0.56 \mathrm{~g}$ & $4.97 \pm 0.62$ a & $5.30 \pm 0.45$ a-d \\
\hline Hawk/Artvin & $6.31 \pm 0.33$ a & $5.58 \pm 0.30 \mathrm{e}$ & $0.81 \pm 0.29$ a & $4.18 \pm 0.26 \mathrm{ef}$ & $4.82 \pm 0.79$ a & $5.32 \pm 0.69$ a-d \\
\hline Artvin/Artvin & $6.41 \pm 0.34$ a & $4.67 \pm 0.23$ а & $0.65 \pm 0.22$ а & $2.76 \pm 0.54 \mathrm{ab}$ & $4.11 \pm 0.71$ a & $4.82 \pm 0.73 \mathrm{ab}$ \\
\hline Artvin & $6.00 \pm 0.31$ a & $4.72 \pm 0.29$ a-c & $0.61 \pm 0.33$ a & $4.11 \pm 0.21 \mathrm{de}$ & $4.47 \pm 0.33$ a & $5.04 \pm 0.19$ a-c \\
\hline Köksal/Naomi & $5.97 \pm 0.65$ a & $5.59 \pm 0.21 \mathrm{e}$ & $0.85 \pm 0.39$ a & $3.95 \pm 0.17 \mathrm{de}$ & $4.42 \pm 0.38$ a & $5.91 \pm 0.71 \mathrm{~cd}$ \\
\hline AGR703/Naomi & $6.22 \pm 0.21 \mathrm{a}$ & $5.44 \pm 0.31 \mathrm{de}$ & $0.86 \pm 0.34$ а & $2.75 \pm 0.43$ ab & $4.96 \pm 0.72$ a & $5.74 \pm 0.54 \mathrm{~b}-\mathrm{d}$ \\
\hline Vista/Naomi & $6.21 \pm 0.42$ a & $5.31 \pm 0.52$ a-e & $0.84 \pm 0.35 a$ & $2.55 \pm 0.29$ a & $4.97 \pm 1.06$ a & $5.45 \pm 0.54 a-d$ \\
\hline Yula/Naomi & $6.14 \pm 0.56$ a & $5.38 \pm 0.29$ c-e & $0.81 \pm 0.34$ a & $3.29 \pm 0.50 \mathrm{bc}$ & $4.03 \pm 0.51$ a & $5.19 \pm 0.59$ a-d \\
\hline Burdur/Naomi & $6.38 \pm 0.31$ а & $5.15 \pm 0.33$ a-e & $0.76 \pm 0.36$ a & $2.79 \pm 0.23 \mathrm{ab}$ & $4.73 \pm 0.53$ a & $5.33 \pm 0.46$ a-d \\
\hline Mardin/Naomi & $6.33 \pm 0.59$ a & $5.26 \pm 0.64$ a-e & $0.68 \pm 0.26$ a & $4.44 \pm 0.33 \mathrm{e}-\mathrm{g}$ & $4.63 \pm 0.70$ a & $5.10 \pm 0.58$ a-c \\
\hline Hawk/Naomi & $6.24 \pm 0.32$ a & $5.34 \pm 0.19$ b-e & $0.78 \pm 0.28$ а & $3.55 \pm 0.30 \mathrm{~cd}$ & $4.19 \pm 0.94$ a & $5.28 \pm 0.44$ a-d \\
\hline Naomi/Naomi & $6.09 \pm 0.32$ a & $4.69 \pm 0.28$ ab & $0.67 \pm 0.32$ а & $2.97 \pm 0.35$ a-c & $4.02 \pm 0.67$ a & $4.60 \pm 0.23$ a \\
\hline Naomi & $6.17 \pm 0.16$ а & $4.84 \pm 0.31$ a-d & $0.63 \pm 0.28$ a & $3.94 \pm 0.28 \mathrm{de}$ & $4.67 \pm 0.54 a$ & $5.34 \pm 0.56$ a-d \\
\hline CV $(\%)$ & 2.29 & 5.95 & 12.11 & 21.01 & 7.56 & 7.26 \\
\hline Uygulama & \multicolumn{2}{|c|}{$\star \star$} & \multicolumn{2}{|c|}{$\star *$} & \multicolumn{2}{|c|}{$* *$} \\
\hline Kombinasyon & \multicolumn{2}{|c|}{ ** } & \multicolumn{2}{|c|}{$* *$} & \multicolumn{2}{|c|}{ ** } \\
\hline $\begin{array}{l}\text { KombinasyonX } \\
\text { Uygulama }\end{array}$ & \multicolumn{2}{|c|}{ ** } & \multicolumn{2}{|c|}{$\star *$} & \multicolumn{2}{|c|}{$* *$} \\
\hline
\end{tabular}

Aynı sütunda farklı harfi alan ortalamalar arasındaki farklıık önemlidir ( $0 \leq 0.01$ ). Ortalamalar arası farklııklar Duncan testi ile belirlenmiștir. **:

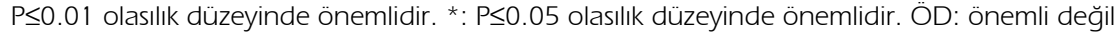


așılı Artvin/Artvin, en yüksek değer 5.63ะ0.22 ile Burdur/Artvin kombinasyonunda elde edilmiștir. Çalıșmadan elde edilen sonuçlar, önceki bazı çalıșmalarla uyumlu bulunmuștur. Krauss vd. (2006), tuzluluğun meyve suyu pH'sını belirgin bir șekilde azalttığını saptamıș olup, Colla vd. (2006) de, tuzlu koșullarda așilı kavun bitkilerinin meyvelerinde $\mathrm{pH}$ seviyesinin așısızlara göre daha düșük olduğunu belirlemișlerdir.

\section{Meyve suyunda titre edilebilir asitlik bakımından ortaya çıkan değișimler}

Kontrol bitkilerindeki titre edilebilir asit miktarı $0.61 \pm 0.33-0.89 \pm 0.39 \mathrm{mval} 100 / \mathrm{ml}$ arasında değișmiștir. Uygulamalar arasındaki ve așı kombinasyonları arasındaki farklılık istatistiksel olarak $p \leq 0.01$ düzeyinde önemlilik gösterdiği gibi, bu özellik bakımından 'uygulamaxkombinasyon' interaksiyonu da önemli bulunmuștur. Tuz uygulamaları meyvedeki asitlik miktarı değerini çok yükseltmiștir. En yüksek titre edilebilir asitlik değeri

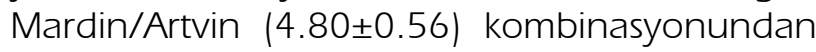
elde edilirken, en düșük değer Vista /Naomi (2.55 \pm 0.29$)$ kombinasyonunda belirlenmiștir (Cizelge 3).

Titre edilebilir asitlik meyve kalitesiyle ilișkilendirilen bir özelliktir. Krauss vd. (2006) ile Trajkova vd. (2006), bitkilerin stres altında iken topraktan su alımına devam edebilmek ve ozmotik uyumu sağlayabilmek üzere yüksek seviyede TA ve TSÇKM değerleri olușturduklarını bildirmișlerdir. Tuzluluğun TA oranını artırdığı, önceki çalıșmalarda Niedziela vd. (1993) ve Kahlaoui vd. (2011) tarafından da belirtilmektedir. Geboloğluvd. (2011), TAözelliğindeki farklııkların anaçlardan ziyade çeșitten kaynaklanan yapıda olabileceğini ifade etmektedir.

Toplam suda çözünebilir kuru madde miktarı (TSÇKM) bakımından ortaya çıkan değișimler

Kontrol bitkilerindeki TSÇKM oranı \% $4.02 \pm 0.67$ ile $4.97 \pm 1.06$ arasında değișmiștir (Çizelge 3). Uygulamalar arasındaki ve așı kombinasyonları arasındaki farklıık istatistiksel olarak $p \leq 0.01$ düzeyinde önemlilik gösterdiği gibi, bu özellik bakımından 'uygulamaxkombinasyon' interaksiyonu da önemli bulunmuștur. Tuz uygulanan bitkilerin meyvelerindeki TSÇKM oranı artmıștır. Denemede yer alan uygulamalar arasında en yüksek TSÇKM oranı AGR703/Artvin (6.08 \pm 0.99 ) ile Köksal/ Artvin (6.05 \pm 0.40$)$ ve en düșük oran Naomi/
Naomi (4.60 \pm 0.23$)$ kombinasyonlarından elde edilmiștir. Karbonhidrat biriktirme yeteneği, birçok çalıșmada tuz stresi karșısında bitkilerin ozmotik uyum sağlayabilmeleri için hayati önem tașıyan bir özellik olarak rapor edilmektedir (Eisa vd., 2012). Ünlükara vd. (2010) ayçiçeği bitkisine ait farklı dayanım seviyelerindeki genotipleri tuzlu koșullarda yetiștirmiș, stres altında șekerlerin arttığını, bu artıșların tuza tolerant genotiplerde daha fazla olduğunu belirlemișlerdir. Denemede kullanılan tüm anaç/kalem kombinasyonlarında TSÇKM miktarlarında artıș meydana gelmiștir. Turhan vd. (2009) ise, bu özelliğin anaç genotipine kuvvetli bir șekilde bağlı olarak ortaya çıktığını öne sürmektedir.

\section{Ortalama meyve ağırığı bakımından ortaya çıkan değișimler}

Uygulamalar arasındaki ve așı kombinasyonları arasındaki farklıık istatistiksel olarak $p \leq 0.01$ düzeyinde önemlilik gösterdiği gibi, bu özellik bakımından 'uygulama x kombinasyon' interaksiyonu da önemli bulunmuștur. Kontrol bitkilerinde ortalama meyve ağırlıkları 95-128 9 olarak belirlenmiș olup istatistiksel olarak uygulamalar arasındaki farklılık önemli çıkmıștır. Așılı bitkilerin meyvelerinin ağırlığı așısızlara göre farklı olduğu gibi, kalem olarak kullanılan iki çeșidin arasında da farklılıklar belirlenmiștir. Tuz uygulamaları meyve ağırlığını azaltıcı etki yapmıștır (Çizelge 4). Kontrol uygulaması ve tuz stresi altında yetiștirilen bitkilerde en düșük ve en yüksek değerler sırasıyla Artvin/Artvin kombinasyonunda $(94.99 \pm 11.08$ ile $62.00 \pm 5.74$ g) ve Vista/Naomi kombinasyonunda $(128.00 \pm 10.73$ ile $109.19 \pm 2.70$ g) aralığında elde edilmiștir. Khah vd. (2006) ve Turhan vd. (2009) de, anaç kullanımının domateste verim ve meyve özelliklerini olumlu etkilediğini rapor etmektedir. Bu durum, daha iyi su ve besin maddesi alma kapasitesine sahip anaçların pozitif etkileri olarak açıklanmaktadır. Ayrıca Bletsos vd. (2003) ve Passam vd. (2005), patlıcanda așılamanın meyve büyüklüğünü artırıcı etki yaptığını bildirmișlerdir.

\section{Ortalama meyve çapı bakımından ortaya çıkan değișimler}

Așilı veya așısız Artvin veya Naomi $F_{\text {, }}$ bitkilerinden olușan 18 farklı kombinasyona ait kontrol ve tuz uygulamasında hasat dönemindeki meyvelerin meyve çapları belirlenmiștir (Çizelge 
Çizelge 4. Tuz stresi sonunda meyve ağırlığı (g), meyve çapı (mm) ve bitki bașına toplam verim (kg) değerleri

Table 4. At the end of salt stress, fruit weight (g), fruit diameter ( $\mathrm{mm}$ ) and total yield per plant (kg) values

\begin{tabular}{|c|c|c|c|c|c|c|}
\hline \multirow{2}{*}{ Kombinasyonlar } & \multicolumn{2}{|c|}{ Meyve ağırlığı (g) } & \multicolumn{2}{|c|}{ Meyve çapı (mm) } & \multicolumn{2}{|c|}{ Bitki bașına toplam verim (kg) } \\
\hline & Kontrol & Tuz & Kontrol & Tuz & Kontrol & Tuz \\
\hline Köksal/Artvin & $109.01 \pm 5.03 a-c$ & $93.00 \pm 3.98 \mathrm{f}-\mathrm{h}$ & $46.13 \pm 7.28$ a-d & $42.70 \pm 2.79 \mathrm{bc}$ & $1.12 \pm 0.46$ a-c & $0.53 \pm 0.22 a-c$ \\
\hline AGR703/Artvin & $107.00 \pm 6.87 \mathrm{ab}$ & $93.00 \pm 3.89 \mathrm{f}-\mathrm{h}$ & $44.20 \pm 4.12 \mathrm{a}$ & $40.89 \pm 3.45 a b$ & $1.91 \pm 1.19$ a-e & $0.85 \pm 0.31 \mathrm{bc}$ \\
\hline Vista/Artvin & $110.00 \pm 6.46$ a-c & $95.00 \pm 5.09 \mathrm{~g}-\mathrm{i}$ & $45.53 \pm 5.06$ a-c & $41.93 \pm 5.67 \mathrm{bc}$ & $1.73 \pm 0.84$ a-e & $1.82 \pm 0.20 \mathrm{~d}$ \\
\hline Yula/Artvin & $106.00 \pm 29.27 \mathrm{ab}$ & $84.00 \pm 3.85 \mathrm{~d}-\mathrm{f}$ & $47.43 \pm 3.19$ a-f & $43.45 \pm 3.27 \mathrm{~b}-\mathrm{d}$ & $1.91 \pm 0.83$ a-e & $0.94 \pm 0.27 c$ \\
\hline Burdur/Artvin & $98.00 \pm 4.77$ а & $82.00 \pm 4.86$ c-e & $45.11 \pm 2.47 \mathrm{ab}$ & $41.86 \pm 2.95$ a-c & $1.26 \pm 0.73$ a-d & $0.58 \pm 0.27$ a-c \\
\hline Mardin/Artvin & $99.00 \pm 6.90 \mathrm{a}$ & $74.00 \pm 7.38 \mathrm{bc}$ & $46.78 \pm 8.41$ a-e & $42.34 \pm 3.95 \mathrm{bc}$ & $1.14 \pm 0.68$ a-d & $0.71 \pm 0.39$ a-c \\
\hline Hawk/Artvin & $105.00 \pm 7.09 a b$ & $87.00 \pm 4.71 \mathrm{e}-\mathrm{g}$ & $47.65 \pm 4.77 \mathrm{a}-\mathrm{g}$ & $43.50 \pm 2.91 \mathrm{~b}-\mathrm{d}$ & $1.15 \pm 0.69$ a-d & $0.50 \pm 0.28$ a-c \\
\hline Artvin/Artvin & $94.99 \pm 11.08$ a & $62.00 \pm 5.74 a$ & $44.45 \pm 3.68 a$ & $38.14 \pm 2.93 \mathrm{ab}$ & $0.97 \pm 0.21 \mathrm{ab}$ & $0.38 \pm 0.13 a b$ \\
\hline Artvin & $97.00 \pm 6.49$ a & $65.00 \pm 6.23 a b$ & $44.56 \pm 3.55 a$ & $36.36 \pm 3.45$ a & $0.73 \pm 0.29$ a & $0.18 \pm 0.07$ a \\
\hline Köksal/Naomi & $125.00 \pm 5.48 \mathrm{~cd}$ & $105.00 \pm 7.02 \mathrm{jk}$ & $54.77 \pm 2.68 \mathrm{~g}$ & $50.66 \pm 3.13 \mathrm{e}$ & $2.41 \pm 1.13 \mathrm{de}$ & $0.78 \pm 0.28 \mathrm{bc}$ \\
\hline AGR703/Naomi & $120.00 \pm 6.42 \mathrm{~b}-\mathrm{d}$ & $105.24 \pm 3.49 \mathrm{jk}$ & $54.43 \pm 1.67 \mathrm{fg}$ & $50.13 \pm 2.74 \mathrm{e}$ & $2.62 \pm 0.97 \mathrm{e}$ & $1.00 \pm 0.38 c$ \\
\hline Vista/Naomi & $128.00 \pm 10.73 d$ & $109.19 \pm 2.70 \mathrm{k}$ & $53.78 \pm 3.16 \mathrm{e}-\mathrm{g}$ & & $2.12 \pm 0$. & $0.83 \pm 0.43 \mathrm{bc}$ \\
\hline Yula/Naomi & $121.00 \pm 8.58 \mathrm{~b}-\mathrm{d}$ & $101.40 \pm 6.96 \mathrm{~h}-\mathrm{k}$ & $53.32 \pm 1.69 \mathrm{~d}-\mathrm{g}$ & $48.68 \pm 2.74 \mathrm{de}$ & $2.02 \pm 0.85$ b-e & $0.91 \pm 0.44 \mathrm{c}$ \\
\hline Burdur/Naomi & $124.00 \pm 3.70 \mathrm{~cd}$ & $98.70 \pm 7.69$ h-j & $52.21 \pm 4.46 \mathrm{~b}-\mathrm{g}$ & $48.40 \pm 2.89 \mathrm{de}$ & $1.82 \pm 0.89$ a-e & $1.81 \pm 0.48 d$ \\
\hline Mardin/Naomi & $119.00 \pm 5.33 \mathrm{~b}-\mathrm{d}$ & $84.61 \pm 6.14 \mathrm{~d}-\mathrm{f}$ & $52.72 \pm 3.19 \mathrm{c}-9$ & $47.18 \pm 2.08$ c-e & $2.05 \pm 0.69$ b-e & $0.84 \pm 0.39 \mathrm{bc}$ \\
\hline Hawk/Naomi & $124.00 \pm 6.57 \mathrm{~cd}$ & $103.04 \pm 6.76 \mathrm{i}-\mathrm{k}$ & $53.54 \pm 4.07 \mathrm{e}-\mathrm{g}$ & $49.04 \pm 3.13 \mathrm{e}$ & $2.34 \pm 0.49$ c-e & $0.81 \pm 0.33 b c$ \\
\hline Naomi/Naomi & $118.00 \pm 7.35 \mathrm{~b}-\mathrm{d}$ & $78.71 \pm 6.90 \mathrm{c}-\mathrm{e}$ & $51.12 \pm 3.93 \mathrm{a}-\mathrm{g}$ & $42.17 \pm 2.82 \mathrm{bc}$ & $1.09 \pm 0.49$ a-c & $0.37 \pm 0.21 \mathrm{ab}$ \\
\hline Naomi & $120.00 \pm 13.07 \mathrm{~b}-\mathrm{d}$ & $76.08 \pm 3.62 \mathrm{~cd}$ & $52.05 \pm 4.49 \mathrm{~b}-\mathrm{g}$ & $40.91 \pm 3.82 \mathrm{ab}$ & $0.99 \pm 0.55 \mathrm{ab}$ & $0.37 \pm 0.28$ ab \\
\hline CV $(\%)$ & 9.65 & 15.80 & 8.03 & 9.76 & 35.38 & 55.47 \\
\hline & \multicolumn{2}{|c|}{ ** } & \multicolumn{2}{|c|}{$* *$} & \multicolumn{2}{|c|}{ ** } \\
\hline Kombinasyon & \multicolumn{2}{|c|}{ ** } & \multicolumn{2}{|c|}{$\star \star$} & \multicolumn{2}{|c|}{ ** } \\
\hline $\begin{array}{l}\text { KombinasyonX } \\
\text { Uygulama }\end{array}$ & \multicolumn{2}{|c|}{ ** } & \multicolumn{2}{|c|}{ ÖD } & \multicolumn{2}{|c|}{ ** } \\
\hline
\end{tabular}

Aynı sütunda farklı harfi alan ortalamalar arasındaki farklıık önemlidir ( $\rho \leq 0.01$ ). Ortalamalar arası farklılıklar Duncan testi ile belirlenmiștir.

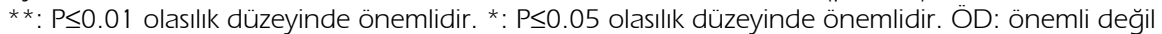

4). Uygulamalar arasındaki ve așı kombinasyonları arasındaki farklılık istatistiksel olarak $\mathrm{p} \leq 0.01$ düzeyinde önemlilik göstermiștir. Kontrol bitkilerindeki meyve çapları 44.20 ile 54.77 $\mathrm{mm}$ arasında değișmiștir ve istatistiksel olarak uygulamalar arasında farklılık önemli bulunmuștur.

Tuz uygulanan bitkilerin meyvelerindeki meyve çapları azalmıștır. Denemede yer alan uygulamalar arasında en yüksek meyve çapı değeri Köksal/ Naomi (50.66 $3.13 \mathrm{~mm})$ kombinasyonundan, en düșük olanı ise Artvin $(36.36 \pm 3.45 \mathrm{~mm})$ genotipinden elde edilmiștir. Davis vd. (2008), bitkilerdeki meyve büyüklüğü, verim ve kalite parametrelerinin kalemin genotipi ve cevre koșullarından etkilendiğini, fakat anaçların da bitki büyümesi ve kalite parametreleri üzerinde etki sahibi olduğunu bildirmektedir. Patlıcanda anaç kullanımının performans üzerindeki etkilerini inceleyen Gisbert vd. (2011), așılamanın meyve uzunluğunu, genișliğini ve meyve indeksini artırdığını belirlemișlerdir. Benzer sonuçları tespit eden Aloni vd. (2010) bu durumun, anaç vigorunun yüksekliği ve anaçta olușan hormonların etkisinden kaynaklandığını ileri sürmektedir.

\section{Bitki bașına toplam verim bakımından ortaya çıkan değișimler}

Yetiștirme dönemi boyunca beș haftasını dolduran meyveler toplanarak tartılmıș ve toplam bitki bașına verim hesaplanmıș ve elde edilen değerler Çizelge 4'de verilmiștir. 18 farklı kombinasyon içerisinde ortalama bitki bașına verim bakımından en yüksek değerler Naomi’nin yer aldığı uygulamalardan elde edilmiștir. Uygulamalar arasındaki ve așı kombinasyonları arasındaki farklılık istatistiksel olarak $\mathrm{p} \leq 0.01$ düzeyinde önemlilik gösterdiği gibi, bu özellik bakımından 'uygulama x kombinasyon' interaksiyonu da önemli bulunmuștur.

Kontrol bitkileri içinde enyüksekverimAGR703/ Naomi (2.62 $\pm 0.97 \mathrm{~kg})$ kombinasyonundan elde edilirken en düșük Artvin $(0.73 \pm 0.29 \mathrm{~kg})$ genotipinden elde edilmiștir. Tuzlu koșullarda en yüksek verim Vista/Artvin $(1.82 \pm 0.20 \mathrm{~kg})$ kombinasyonundan elde edilirken en düșük 
Artvin $(0.18 \pm 0.07 \mathrm{~kg})$ genotipinde bulunmustur. Her kombinasyonunun kendi kontrolü ile karșılaștırılması sonucunda elde edilen \% değișim veya oransal değișim, kombinasyonların performansını ortaya koyması nedeniyle kullanılmaktadır. Tuz uygulaması sonucu en düșük değeri veren Artvin genotipi yaklașık \%24.7 oranında verim kaybına uğrarken, en yüksek verimin elde edildiği Vista/Artvin genotipi \%5.2 oranında değer artıșı göstermiștir. Kontrolde en yüksek değerin elde edildiği AGR703/ Naomi kombinasyonunda tuzlu koșullara \%38.2 oranında verim kaybı görülmüștür. Wan vd. (2010), hıyarda tuz stresinin verimi azalttığını, her bir birim AC artıșının \%5.7 oranında verim kaybı olușturduğunu belirlemișlerdir. Verim kaybının bileșenleri olarak meyve ağırlığı ve meyve sayısındaki düșüșler gösterilmektedir. Patlıcanda tuzlu sulama suyu ile sulanan bitkilerde meyve verimi, meyve ağırlığı ve sayısındaki azalmalar nedeniyle olumsuz etkilenmiștir (Ünlükara vd., 2010). Așılı bitki kullanımı tekniğinin tuzlu koșullarda verimi artırdığı Rivero vd. (2003) tarafından kanıtlanmıștır. Anaçların kuvvetli (vigor) kök sistemlerinin daha iyi su ve besin maddesi alabilmesi sayesinde verim kaybının așılı bitkilerde daha az ortaya çıtığı Ruiz vd. (1997) tarafından da belirtilmektedir.

\section{SONUC̣LAR}

Kullanılan 18 adet anaç/kalem kombinasyona ait patıcan bitkilerinin tuz stresine karșı gösterdiği performanslar farklı olmuștur. İncelenen değerler

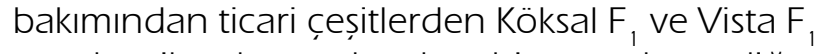
anaçları ile olușturulan kombinasyonların diğer kombinasyonlara göre daha iyi sonuçlar verdiği ve bitkinin tuz toleransını artırdığı belirlenmiștir. Bununla birlikte anaç olarak kullanılan Burdur ıslah hattı, ticari anaçlarla tuz toleransı bakımından rekabet edebilir nitelikte bulunmuș ve bu genotipin türler arası melezlemelerde kullanılması, biotik stres faktörleri belirlenerek hastalıklara dayanım kazandırıması gibi çalıșmaların yapılması yoluyla anaç geliștirme programlarına dahil edilebileceği belirlenmiștir.

\section{KAYNAKLAR}

Aktas H, Daler S, Ozen O, Gencer K, Bayindir D, Erdar I (2013). The effect of some growing substrate media on yield and fruit quality of eggplant grown and irrigated by drip irrigation system in greenhouse. Infrastruktura I Ekologia Terenów Wiejskich Infrastructure and Ecology of Rural Areas $\mathrm{Nr}$ 1/lı/2013, Polska Akademia Nauk, Oddział w Krakowie, pp. 5-11.
Aloni B, Cohen R, Karni L, Aktas H, Edelstein M (2010). Hormonal signaling in rootstock-scion interactions. Scientia Horticulturae, 127: 119-126.

Altunlu $\mathrm{H}$ (2011). Așllamanın domateste kuraklık stresine etkileri. The effect of graftıng against drought stress in tomatoes. Doktora tezi. Ege Universitesi Fen Bilimleri Enstitüsü, İzmir.

TUIK (2017), Turkish Statistical Institute, (www.tuik.gov. tr), Access date: 6.11.2017.

Bletsos F, Thanassoulopoulos C, Roupakias D (2003). Effect of grafting on growth, yield and Verticillium wilt of eggplant. HortScience, 38:183-186.

Borghesi E, Gonzalez-Miret ML, Escudes-Martinez A (2011). Effects of salinity stress on carotenoids, anthocyanins, and color of diverse tomato genotypes. Journal of Agricultural and Food Chemistry, 59(21): 11676-82.

Boyacı Cl (2008). Bilinmeyen yönleri ile patlıcan. Meyve ve Sebze Dünyası, 1(7): 56-57.

Colla G, Rouphael Y, Cadarelli M, Rea, E (2006). Effect of salinity on yield, fruit quality, leaf gas exchange, and mineral composition of grafted watermelon plants. HortScience., 41 (3): 622-627.

Colla G, Rouphae, Y, Leonardi C, Bie Z (2010). Role of grafting in vegetable crops grown under saline conditions. Scientia Horticulturae, 127: 147-155.

Cürük S, Dasgan HY, Mansuroglu S, Kurt S, Mazmanoglu M, Tarla G, Durgac C (2010). Leaf mineral composition of grafted eggplant grown in soil infested with Verticillium and root-knot nematods. Pesquisa Agropecuária Brasileira, 45(8): 879-885.

Daunay M, Janick J (2007). History and iconography of eggplant. Chronica Horticulture. 47(3): 16-22.

Davis AR, Perkins-Veazie P, Hassell R, Levi A, King SR, Zhang $X$ (2008). Grafting effects on vegetable quality, HortScience. 43(6).

Eisa S, Hussin S, Geissler N. ve Koyro, HW (2012). Effect of $\mathrm{NaCl}$ salinity on water relations, photosynthesis and chemical composition of quinoa (Chenopodium quinea Wild.) as a potential cash crop halophyte. AJCS, 6(2): 357368.

Estan MT, Martinez-Rodriguez MM, Perez-Alfocea F, Flowers TJ, Bolarin MC (2005). Grafting raises the salt tolerance of tomato through limiting the transport of sodium and chloride to the shoot. Journal of Experimental Botany, 56(412): 703-712.

Fernandez-Garcia N, Cerda A, Carvajal M (2003). Grafting, a useful technique for improving salinity tolerance of tomato? Acta Horticultural, 609: 251-256.

Geboloğlu N, Yılmaz E, Çakmak P, Aydın M, Kasap $Y$ (2011). Determining of the yield, quality and nutrient content of tomatoes grafted on different rootstocks in soilless culture. - Scientific Research and Essays, 6(10): 2147-2153

Gisbert C, Prohens J, Nuez F (2011). Performance of eggplant grafted onto cultivated, wild, and hybrid materials of eggplant and tomato. International Journal of Plant Production, 5(4): 367-38. 
Hossain MM, Nonami H (2012). Effect of salt stress on physiological response of tomato fruit grown in hydroponic culture system. Horticultural Science (Prague), 39(1): 26-32.

Kahlaoui B, Hachicha M, Rejeb S, Rejeb MN, Hanchi $B$, Misle $E$ (2011). Effect of saline water on tomato under subsurface drip irrigation: Nutritional and foliar aspects, Journal of Soil Science and Plant Nutrition, 11(1): 69 - 86.

Karaçalı i (1993). Bahçe Ürünlerinin Muhafazası ve Pazarlanması. EÜZF Yayınları, No: 494, P.444.

Khah EM, Kakava E, Mavromatis A, Chachalis D, Goulas $C$ (2006). Effect of grafting on growth and yield of tomato (Lycopersicon esculentum Mill.) in greenhouse and openfield. Journal of Applied Horticulture, 8: 3-7.

King SR, Davis AR, Zhang X, Crosby K (2010). Genetics, breeding and selection of rootstocks for Solanaceae and Cucurbitaceae. Scientia Horticulturae, 127: 106-111.

Krauss S, Schnitzler W, Grassmann J, Woltike M (2006). The influence of different electrical conductivity values in a simplified recirculating soilless system on inner and outer fruit quality characteristics of tomato. Journal of Agricultural and Food Chemistry, 54: 441-448.

Kușvuran Ș, Dașgan HY, Abak K (2011). Responses of different melon genotypes to drought stress. Yuzuncu Yıl University Journal of Agricultural Sciences, 21: 209-219.

Libia I, Trejo-Téllez Fernando C. Gómez-Merino (2012). Nutrient Solutions for Hydroponic Systems, Hydroponics - A Standard Methodology for Plant Biological Researches, Dr. Toshiki Asao (Ed.), ISBN: 978- 953-51-0386-8, InTech, Available from: http://www.intechopen.com/books/ hydroponics-a-standardmethodology-for-plant-biologicalresearches/nutrient-solutions-for-hydroponic-systems

Niedziela Jr CE, Nelson PV, Willits DH, Peel MM (1993). Short-tenn salt-shock effects on tomato fruit quality, yield, and vegetative prediction of subsequent fruit quality. American Society for Horticultural Science, 118:12-16.

Oztekin GB, Tuzel Y (2011). Salinity response of some tomato rootstocks at seedling stage. African Journal of Agricultural Research, 6(20): 4726-4735.

Passam HC, Stylianoy M, Kotsiras A (2005). Performance of eggplant grafted on tomato and eggplant rootstocks. European Journal of Horticultural Science, 70: 130-134.

Rivero RM, Ruiz JM, Sanchez E, Romero L (2003). Does grafting provide tomato plants an advantage against $\mathrm{H} 2 \mathrm{O} 2$ production under conditions of thermal shock. Physiologia Plantarum, 117: 44-50

Romero-Aranda MR, Soria T, Cuartero J (2001). Tomato plant-water uptake and plant-water relationships under saline growth conditions. Plant Science, 160(2): 265-272.
Ruiz JM, Belakbir A, López-Cantarero I, Romero L (1997). Leaf-macronutrient content and yield in grafted, melon plants. A model to evaluate the influence of rootstock genotype. Scientia Horticulturae, 71:227-234.

Sangtarashani ES, Tabatabaei SJ, Bolandnazar S (2013). Yield, Photosynthetic efficiency and Quality parameters of Cherry tomato as affected by $\mathrm{Ca} 2+$ and $\mathrm{K}+$ under $\mathrm{NaCl}$ salinity. , 5(12): 1280-1288.

Savvas D, Colla G, Rouphael Y, Schwarz D (2010). Amelioration of heavy metal and nutrient stress in fruit vegetables by grafting. Scientia Horticulturae, 127: 156-161.

Sivritepe N, Sivritepe HO, Celik H, Katkat AV (2010). Salinity responses of grafted grapevines: Effects of scion and rootstock genotypes. Notulae Botanicae Horti Agrobotanici Cluj-Napoca, 38(3): 193-201.

Sönmez K (2014). Likopen, ß-Karoten and Morfolojik Özellikler Bakımından Yerel Sofralık Domateslerde Genotip X Çevre İnteraksiyonu. Doktora tezi, Ankara Üniversitesi, Fen Bilimleri Enstitüsü, Ankara.

Trajkova F, Papadantonakis N, Savvas D (2006). Comparative effects of $\mathrm{NaCl}$ and $\mathrm{CaCl} 2$ salinity on cucumber grown in a closed hydroponic system. HortScience, 41 : 437441.

Tümbilen Y, Frary A, Mutlu S, Doganlar S (2011). Genetic diversity in Turkish eggplant (Solanum melongena) varieties as determined by morphological and molecular analysis. International Research Journal of Biotechnology, 2(1): 16-25.

Turhan A, Seniz V, Kuscu H (2009). Genotypic variation in the response of tomato to salinity. African Journal of Biotechnology,8(6): 1062-1068.

Ünlükara A, Kurunc A, Duygukesmez G, Yurtseven E, Suarez DL (2010). Effects of salinity on eggplant (Solanum melongena L.) growth and evapotranspiration. Irrigation and Drainage, 59: 203-214.

Wan S, Kang Y, Wang D, Liu SP (2010). Effect of saline water on cucumber (Cucumis sativus L.) yield and water use under drip irrigation in North China. Agriculture water management. Doi: 10.1016/J.agwat.2010.08.003.

Yașar F (2003). Tuz stresi altındaki patlıcan genotiplerinde bazı Antioksidant enzim aktivitelerinin in vitro ve in vivo olarak incelenmesi. Doktora tezi, Yüzüncü Yıl Üniversitesi Fen Bilimleri, Van.

Yașar F, İhtiyaroğlu S, Uzal Ö, Ellialtıŏlu Ș (2011). Karpuzda (Citrullus lanatus (Thunb.) Mansf.) Tuza Tolerans Özelliği ile Tohum İriliği ve Kotiledon Yaprağı Arasındaki İlișkinin İncelenmesi. Vı. Ulusal Bahçe Bitkileri Kongresi, 4-8 Ekim, Șanlıurfa. 